\title{
CULTURAL SIGNALS IN UNDERSTANDING FIRST-YEAR STUDENT ENGAGEMENT: HOW CAN UNIVERSITIES BECOME MORE CULTURALLY SENSITIVE? THE CASE OF A RURAL SOUTH AFRICAN UNIVERSITY
}

\section{J. S. Mkhize*}

School of Education in the discipline of Adult Education

e-mail: mkhizejs@gmail.com / https://orcid.org/0000-0003-2528-6626

\section{Ramrathan}

School of Education

e-mail: ramrathanp@ukzn.ac.za / https://orcid.org/0000-0001-9963-0675

*University of KwaZulu Natal

Durban, South Africa

\section{ABSTRACT}

High levels of student engagement, particularly in first-year university students are associated with a wide range of educational practices and conditions including students' social and academic integration into the institutions of higher education. These educational practices link student engagement with students' performance to students' academic achievement leading to graduate throughputs. The study sought to understand first-year student experiences of the university's ability to provide an academic environment that is conducive and responsive to learning for students with unique characteristics. Data were generated from first-year students enrolled for a Bachelor of Education degree in a rural South African University using focus group interviews with students that were purposively selected from this cohort using areas of specialization as the criteria. Also, one-on-one interviews were conducted with students that had performed well in their examinations as well as those that did not perform so well. The results revealed that students' cultural orientations are a precursor of how student would thrive in their academic journey and that students' cultural repertoires influence the extent to which students integrate and engage both academically and socially into the university environment. In this article, we argue that students' cultural orientations have implications in their academic performance and social integration in their first year of study at university. This article contributes to the ongoing research agenda of student engagement, academic success, first-year student experience and throughput employing students' cultural signals as another dimension to understand such critical phenomena.

Key Words: Cultural signals, cultural repertoires, cultural orientation, integration, student engagement, cultural capital, academic performance and academic success. 


\section{INTRODUCTION}

There is evidence of substantial research on student access, throughput and graduation rates, with findings suggesting that higher education has significant inefficiencies in these areas as argued in Ramrathan and Pillay (2015) as well as in Hlengwa, McKenna and Njovane (2018). National reports such as the Council on Higher Education's report also highlight these inefficiencies in the South African context (CHE 2019). Krause and Coates $(2008,494)$ cite student engagement as a key factor in student success. Similarly, Strydom, Kuh and Mentz (2010) observed that institutional surveys related to student engagement have been conducted across universities in South Africa. These institutional surveys drew from studies conducted in developed countries like the United States of America, Canada and Australia exploring the student engagement phenomenon in all its depth to find relative solutions to improving firstyear students' experiences and successes.

Vitalstats, an official publication for South Africa's Council on Higher Education of 2017; CHE (2017, 3-4) shows that graduation rates by race in South African Universities have never exceeded 20 per cent since 2012 as Table 1 illustrates.

Table 1: Enrolment and graduation of African students at South African Universities 2012-2017

\begin{tabular}{|l|c|c|c|c|c|c|}
\hline \multicolumn{1}{|c|}{ African students only } & $\mathbf{2 0 1 2}$ & $\mathbf{2 0 1 3}$ & $\mathbf{2 0 1 4}$ & $\mathbf{2 0 1 5}$ & $\mathbf{2 0 1 6}$ & $\mathbf{2 0 1 7}$ \\
\hline Headcount enrolment by race & 66123 & 689503 & 679800 & 696320 & 701482 & 763767 \\
\hline Headcount Graduation by Race & 104935 & 116867 & 122145 & 127237 & 138630 & 147322 \\
\hline Percentage & 16 & 17 & 18 & 18 & 20 & 19 \\
\hline
\end{tabular}

Given the data that are presented in Table 1, we ask questions: Why is it persistently the African students that are dropping out or not coping despite all the interventions made and support given at universities? What is it that is not African in the provision of teaching and learning that could result in the statistics presented? This article takes that vantage point in exploring this persistency and to find out the factors that have come to be realized as cultural symbols that influence the way in which first-year students are engaged with academic work and the way in which they engage with academic staff.

As this study takes a race-based analysis, a case study approach was used in producing empirical data to support the assertions made. A historically black only university was used as a research site. In this article, we argue that the cultural orientation of African students guides their interaction with people and may account for persistently high-drop-out rates and poor academic performance in their first year of study at a university. It is in this focus area that this article attempts to contribute some deeper insights to understanding some of the challenges that rural students experience in a higher education environment. This article, therefore, illuminates 
how African cultural traditions of rural communities influence student engagement particularly during their first year of study.

\section{PUTTING STUDENT ENGAGEMENT INTO CONTEXT}

Fitzgerald et al. (2016, 226-227) argue for a renewed approach to engagement, where institutions of higher education need to rethink their structure, epistemology and pedagogy. In doing so, these authors argue that "not all knowledge and expertise reside in the academy, and that both expertise and great learning opportunities in teaching and scholarship also reside in non-academic settings". Earlier research has consistently linked student engagement to academic achievement. This article does not seek to critique that particular stance but offers a position that requires institutions to rethink existing pedagogies that assume similarities in student backgrounds and consider positions that embrace diversities and consider practices that understand learning opportunities that reside in non-academic settings.

Kahu and Nelson $(2018,59)$ concede that student engagement is widely argued for as a critical phenomenon in higher education, but are concerned that "the mechanisms contributing to the individual student's engagement have not yet been clearly articulated and the term engagement is used differently in various contexts". So, how has student engagement been understood? Student engagement has been understood in many ways; Kuh et al. (2008, 542) define student engagement as that which represents both time and energy which students invest in educationally purposeful activities as well as the efforts institutions devote to using effective educational practices. Similarly, Trowler $(2010,3)$, defines student engagement as that which

“... is concerned with the interaction between the time, effort and other relevant resources invested by both students and their institutions intended to optimize the student experience and enhance the learning outcomes and the development of students and the performance, and reputation of the institution.”

There is evidence in the previous two understandings of student engagement, which suggests a progressive evolution of the concept, from time and energy spent in educationally purposeful activities to an intended optimization of the student's educational experiences.

Kahu and Nelson (2018) claim that students who are engaged with their studies are more likely to succeed academically. Central to Kahu and Nelson's $(2018,59)$ argument which is based on cultural and transitional theories, is that "individual student engagement occurs dynamically within an educational interface at the intersection of the student and their characteristics and background, and the institution and its practices". Kahu and Nelson (2018) bring an argument that purports an educational interface that considers individual student's 
characteristics and background into the student engagement discourse.

There is sufficient evidence in literature which suggests that student engagement is not or should not be limited to time, efforts and resources used by students on academic-related activities like consultations with lecturers as Kuh (2006) and Trowler (2010) have argued. There are other issues to consider, like the extent to which the institutional factors interact with student factors (Meek et al. 2010). Student engagement has also been understood as that which encompasses three critical elements like the behavioural, emotional and cognitive elements of students as Axelson and Flick (2011) suggest. Along the same line of thought, Strydom and Mentz (2010) argue for two critical components of student engagement, which clarify a significant partnership of what institutions do as well as what students do.

This study sought to understand the students' experiences on the university's ability to provide an environment that is conducive to learning for students with unique characteristics. The plethora of literature (Kuh 2006; Strydom and Mentz 2010; Trowler 2010; Axelson and Flick 2011; Kahu and Nelson 2018) on student engagement suggests at least two critical points. Firstly, that student engagement is an accountability measure that provides a general index of student involvement with their learning environment. Secondly, that student engagement is a variable in educational research that is aimed at understanding, explaining and predicting student behaviour in learning environments.

This article focuses on this continuing research agenda, with the purpose of contributing to the discourse of student engagement using the students' cultural orientation as an angle of approach and as phenomenon worth interrogating. We seek to explore how students' cultural repertoires affect student engagement in their first year of study using a rural university as a site. Further, we illuminate the cultural orientation which first-year students possess and present that need to be understood within the context of student engagement phenomenon. In this article, we go beyond the norms of social and academic integration argued for and supported by seasoned scholars in the field of student engagement. We introduce cultural signals as an element for consideration when trying to understand the phenomenon of student engagement.

The study was conducted in one of South Africa's historically disadvantaged rural universities, where the majority of the students reflect a fairly homogeneous culture of the Zulu nation. AmaZulu (The Zulus) are a large majority in South Africa, with their language (as captured in Census 2011, Census in brief) isiZulu being spoken by at least 11587374 million South Africans and understood by at least 24 per cent of the South African population (Statistics South Africa Censors 2012, 23). 


\section{ACCESS, RETENTION, DROP-OUTS, PERFORMANCE AND THROUGHPUT}

Student retention, low throughput rates and poor academic performance have been a major concern across higher education within South African Universities for two and a half decades since the dawn of democracy in 1994. Statistics suggest that 25 per cent of students drop out of university in their first year of study (Scott, Yeld and Hendry 2007). Table 1 of this article illuminates the completion rates to support evidence produced in earlier studies. Of particular concern is that the statistics are racially skewed. Letseka and Maile (2008) also highlight that it is the African students that are the majority, which drops out during the first year of study, a trend that has not yet changed a decade later. Other literature points out that transformation of the South African Higher Education system allowed for a wider and an open access CHE (2016, 24) of students across all race groups to all universities Mdepa and Tshiwula $(2012,19)$ including African student accessing those universities that had in the past been reserved for white minorities only Badat (2010).

The discourse of first-year student dropout, low throughput rates and poor academic performance raises questions. (a) Is it the students that come to universities with a deficit, given the common discourse of poor schooling? This question fits in the student deficit discourse as argued and challenged in McKay and Devlin (2016, 347). (b) Is it because the universities are underprepared to provide a curriculum that is responsive to the diverse needs of first-year students? The discourse on curriculum responsiveness argued in McGhie (2012, 191-193) provides insights on why some university students were less successful than others. While this article may not provide answers to all the questions, it provides a view on students' cultural orientations while at the same time challenging traditional pedagogical practices in the context of learning, teaching and students' academic performances.

First-year students' experience is strongly related to the students' background and is influenced by a range of social, cultural and financial factors of the individual student. In South Africa, there seems to be a constant illumination of diversity of students that enter South African Higher Education Institutions (HEIs). These radiances of student diversity resonate squarely with the transformation agenda of the South African universities and indicative of the possible new ways of student engagement and the calibre of students that access higher education in recent times. This line of thinking and investigation of the student engagement phenomenon begin to highlight the need to critically understand students' demographic factors, their sociopolitical statuses and the effect that these have on student learning, academic engagement and how these relate to (and influence) students' academic performance.

Demographic diversity, as argued in (Van Zyl 2013), is a significant factor in understanding student academic performance. Van Zyl (2013, 235) further extends his 
argument by stating that:

"Although common predictors have been identified, the factors that differentiate between the different population groups should be further investigated to gain a more nuanced understanding of the different aspects that influence the different groups."

While student diversity is a factor in understanding academic performance in the context of a rural university with a fairly homogenous group of students; students' home language and all signs that illuminate individual student's culture need further exploration as another factor that provides a new dimension to the current discourse of student engagement in recent times.

Ramrathan (2013) argues that dropouts are largely amongst black students, citing finance, poor school preparation, inadequate teaching as well as lack of (or) inadequate support at HEIs. In advancing his argument, Ramrathan $(2013,218)$ cautions the universities by stating that:

\footnotetext{
"Universities need to move away from viewing students as particular groupings, like rural students or students from disadvantaged home backgrounds, and begin to view students as individuals influenced by a range of factors that makes each one unique. Group labelling perpetuates group identities and students who are historically from these identity groupings subtly promote an acceptance of this discourse."
}

One of the distinct factors that make university students unique individuals are their cultural orientations, which this article advocates for. Govender (2014) presents an argument that proffers a view that student success cannot be attributed to a single factor. She approaches the discourse of first-year student success at the university from an African concept of Ubuntu. She argues that different manifestations of the philosophy of Ubuntu, whether understood or observed from the participants' side or the retainers' side, all lead to assisting stakeholders in attaining academic success in Higher Education. This article posits that understanding students' cultural orientation could provide academic staff members in institutions of higher education with an additional lens to understand student performance, success, engagement and persistence.

\section{CULTURE AS A PHENOMENON OF STUDENT ENGAGEMENT}

Borrowing from the seminal work of Kroeber and Kluckhohn (1952), it is significant to first lay the groundwork in order to contextualize culture, a term that has multiple meanings. Kroeber and Kluckhohn $(1952,9)$ attest that cultural dimensions of humans and modernization has influenced various specialized fields like criminology, social work and clinical psychology. Whilst one acknowledges that human behaviour has changed drastically over the years, culture 
still defines the customary beliefs, social forms as well as material traits of a racial, religious or social group. In the context of this article, culture includes the characteristic features of everyday existence as diversions or a way of life shared by people in a particular place at a particular time in a particular context. While it is a challenge to reach consensus on a fixed definition of culture; fluidity and evolution of culture are acknowledged in the context of this article.

Keesing $(1974,75)$ argues that cultures are systems of socially transmitted behaviour patterns that serve to relate human communities to their ecological settings. Consistent with the understanding of culture is that it is the integrated pattern of human knowledge, beliefs, and behaviour that depends upon the capacity for learning and transmitting knowledge to succeeding generations (Mesoudi 2016, 485). Cultural signals, as this article would argue, are material traits or sets of visible, understandable and observable human behaviour patterns associated with beliefs shared by and creating an identity of a particular social group. An investigation in Boyd $(2008,138)$ on human learning and cognition posits that "humans uniquely inhibit not just a cognitive niche, but also a cultural niche"; further affirming that human intelligence is strongly influenced by cultural intelligence. In Reckwitz $(2002,195)$, it is argued that "theories of culture are sufficient to provide vocabularies that seek to understand and explain human action and social order by establishing their basis in symbolic codes and schemes that regulate meaning".

\section{METHODOLOGY}

This article samples the results of a bigger study that sought to investigate how first-year students engage with their studies and why these first-year students perform academically in the manner in which they do. The target population were the first-year students who were registered for the first time in the Bachelor of Education at this university. The total population was 1255 students. Data used in the bigger project were obtained in three forms. The first set of data was generated through document analysis. This enabled us to gather data on first-yearstudents' academic performance specifically during the first semester. Further, student records were perused to obtain students' profiles, academic performance and demographic information. Data that were obtained through document analysis were used to guide the selection of the participants in this study. Secondly, three sets of focus group discussions with first-year students enrolled for a Bachelor of Education qualification in a rural South African University. Each focus group had an average of eight student participants who were purposively selected from various areas of specialization in this qualification using data generated from documents. Finally, one-on-one interviews with six students were conducted, where three of the six students 
had had exceptionally high levels of academic performance in the first semester, and the other three had a very low academic performance level.

Data presented and discussed in this article were generated from focus group discussions and interviews. The total number of participants involved in producing data presented in this article is thirty, made up of eighteen females and twelve males. Data that were obtained from these interviews, as well as focus group discussions, were analysed thematically.

\section{The descriptive analyses of the participants in the study}

The participants in this study were students largely mono-racial African students which were not influenced by other race groups. The students were in the second semester of their first year of study enrolled in a rural university and possess unique characteristics. These were black South African students mainly from the northern part of Zululand in KwaZulu Natal. These students were mainly from rural areas and came from families of low socio-economic status. The majority of them were born and raised by parents with reasonably high levels of illiteracy and low to non-employment families. The students were largely first-generation students.

The students registered at this rural university are a fairly homogenous group. The homogeneity is informed amongst other things the mother tongue or home language which is isiZulu that the majority of the students speak as well as a homogeneous African culture strongly rooted in the Zulu traditions. Because all participants were Zulus, the dominant language spoken by most of the students in this rural university is isiZulu. We bring this background to contextualize the evidence that we forthwith present, and considering that culture is understood and transferred through the language, which serves as means of expression of community and national identities.

\section{RESULTS}

There were startling observations that were made during the interview sessions and focus group discussion. A bi-lingual approach was adopted during interviews and focus group session, using both isiZulu and English, but all transcripts were later translated into English. The purpose of conducting the interviews in this way was to enable students to freely express themselves and further enable the study to obtain rich data. There were trends that were noticeable which raised our curiosity to further interrogate what appeared to be the students' cultural signals like the highlight of the strength of students' willingness and ability to work collaboratively in various academic activities. These cultural signals further emerged as we developed the themes during the analyses of qualitative data.

Students with similar or common cultural heritage exhibit common characteristics and 
behaviors that they possess which is common to and entrenched in their culture. These are likely to trigger particular reactions from the observers. In the context of this study, these characteristics were revealed by students that fit the description of cultural homogeneity, monoracialism and common cultural identity. Students display these through signals intentionally or unintentionally in order to convey particular information contained in the meaning in order to enhance their learning inside and outside the regulated teaching and learning environments. The conduits of these signals are language and observable behaviors that communicate special meaning. In the context of this study as alluded to earlier, we further move that cultural signals refer to gestures, dress codes, behaviours, speaking patterns including non-verbal communication that are used in various context in order to communicate specific messages. The cultural signals are associated to a specific group of people, who share common identities in the same environment; in this study we include same cultural heritage and shared dominant religious beliefs. This article calls for institutions to reciprocate these kinds of actions by students with equally responsive interventions.

These noticeable and dominant cultural signals of the participants were much aligned to the culture of the Zulu nation and carry a significant heritage that is necessary for understanding within the discourse of student engagement in HEIs. These cultural signals needed to be further explored on the extent to which they could inform the practice of teaching and learning at a university. Cultural signals are presented in this article to illuminate other factors for consideration in understanding and advancing the research agenda on student engagement.

\section{Common identities: I am because we are!}

During the interviews and the discussions, we observed the students' frequent use of the terms or common nouns that signify common identity signalling the strength and the centrality of collaboration, mutual dependency, brotherhood and sisterhood amongst students. The common nouns like: bafo: which is commonly used by the younger generation to mean brother; others use mfowethu: meaning my brother; Bhuti means older brother. Similarly, sisi refers to older sister; and dadewethu meaning my sister. Finally, the use of the term mkhaya meaning homegirl or home-boy featured prominently during discussions. The significance of home-boy / home-girl was the recognition, promotion and understanding of similar backgrounds by students. This suggests that they may share similar socio-economic contexts, culture as well as background. IsiZulu is not an international language or a language of instruction (except where isiZulu is the subject being taught), but speakers of isiZulu, and the readers of scholarship that seeks to highlight critical knowledge can capitalize on its strength for the benefit of accessing knowledge. 
It is in Bourdieu $(1992,502)$, where an argument is made that linguistic capital affords the holders symbolic power; where the same symbolic power offers power relations between individual speakers or a common group. It is in a language that the personal identity of an individual is realised. We bring the terms above to show how students accord respect to each other which is quite fundamental amongst the Zulu nation. There were no instances where students used personal pronouns when referring to fellow classmates, even in instances where they did not know each other by name; they referred to each other as brothers or sisters, minimizing the use of personal pronouns. This was a way of according each other respect and showing an understanding of common linguistic background as well as common identity. The most common way of addressing people in the Zulu culture, more especially in formal settings is to use titles signifying positions, use of "izithakazelo" (Clan Names) and the third person personal pronouns are preferred even when one is addressing a person directly. Respect, collaboration, mutual dependency became a new feature to bring about common and group identity amongst the student as a collective.

Certain phrases and gestures were used by the students signifying the students' cultural orientations. These included linguistic terms and phrases, gestures and behavioural patterns. Gestures like the use of a clenched fist to point at someone as opposed to using the index finger. Using the clenched fist to point at someone signals respect, solidarity and support. It is these customary beliefs, social forms and material traits of the students that began to inform a collective group identity. As mentioned earlier, these student beliefs and material traits became the characteristic features of students' everyday experiences of teaching and learning at the university. When one focus group responded to a question on how large classes affect their learning, one female participant said: "When the classes were full, and I came late, I found it very uncomfortable to sit on the floor. I cannot sit comfortably on the floor wearing a dress, particularly when the male Lecturer is teaching; even if it is female you cannot just sit anyhow." The reasoning brought by this female respondent portrays a challenge to female students, which is caused by infrastructural challenges, large classes, cultural background and gender stereotypes in a male dominated environment.

Wearing of trousers by females is not very common amongst the majority of black females, particularly those that come from rural areas. Even students that may come from homes in urban areas that have parents that are still strongly rooted in tradition still have challenges of freely expressing themselves with convenient ways of dressing themselves. Female students that were strongly rooted in traditions were partly due to both cultural as well as religious associations with the Nazareth Baptist Church, a strong religious denomination based on African cultural systems with specific focus on Zulu customs and values. This church is also 
called the Shembe church because it was founded by the Prophet Isaiah Shembe. Other female students came from rural households in the areas that are under strict and direct control of the Zulu monarch. The religious group referred to above as well as the Zulu monarch have a strong influence on and observance of customs, cultural practices, traditions and beliefs, including the way in which women are robed and behaved. One female student said: "I am a female; I can't just do things anyhow. You behave in front of elders and males." However, the institution had limited spaces due to large classes. The awkwardness of sitting on the floor in the lecture hall with male lecturer in the front made female students personally aware of their uncomfortableness. Instead of sitting and being relaxed and concentrating on teaching and learning; they became worried about their sitting positions. This, then became a gender-related matter.

Linguistic challenges were another dominant feature amongst students. The lack of competence and confidence in the use of spoken English in front of peers generally posed communication challenges to most of the students. This came about when students had to ask questions during lectures, engage or participate in discussions as one student said:

"When you use 'broken English' some students laugh at you. Others will call you by that wrong phrase or word that you used. It is not easy. Even when you know what to say or how to say it in Zulu, you can't say it."

Poor or low command of English as a spoken language was an inference drawn from this challenge and probably the response to why students found it difficult to make presentations in class or appointments to consult with Lecturers after classes or during set consultation times. The students said they understand English but are not confident to speak it with their lecturers. Students' poor command of English was one of the reasons why students did not consult with lecturers. They were not confident about themselves, and they were reluctant and not comfortable to engage with lecturers.

The idea of respect further challenged and compromised engagement with lecturers partly because the Zulus have a particular way of engaging with adults. It is customary for the young not to talk back to an adult. This situation has caused students not to participate in class discussions where lecturers are involved. This compromised participation. Even when students had good ideas to contribute, they would not do so if those would differ from the lecturer's. This made students not to engage beyond what the lecturer had given because to many students, the lecturer was still the major source of information and knowledge. Unless spoken to, as the Zulu culture and etiquette dictates, children will ordinarily not speak to adults unless invited to speak or asked to speak. 
Some students came to the realisation that they are growing and coming of age. The extent to which students gained independence and freedom channelled some to begin to establish romantic relationships, and it became a challenge to others and a destruction to some as one student said: "The biggest mistake was to propose a girl that was clever in class, she just killed my confidence, worse she did not fall in love with me ...". The life events are inevitable, but to some, the decisions to start building relationships became a challenge as these affected how students engaged in class as they became afraid to make mistakes in class as they did not want to embarrass themselves in front of their girlfriends. The rejection rates were quite high and impacted both male and female students, and these rejections had more personal influence on male students than females.

Students were open to acknowledging their linguistic capital shortcomings, computer illiteracy, poor academic writing and expression in English, indicating these as some of their academic challenges. However, they said despite such challenges, they still learn better from one another. This suggests the power of collaboration in mitigation of their own academic challenges and potential learning insufficiencies. There is evidence to suggest that the Zulu nation has strength in working together and in sharing. This article offers this as an additional lens for a better and more refined understanding of student engagement using collaboration as one example of student engagement agenda from a cultural perspective.

The following are some of the expressions that were used by the students during focus group discussions, and some emerged during the one-on-one interviews. We have carefully selected a few idiomatic and proverbial expressions; particularly those that translate the students' thinking on what informs their engagement practices, the extent to which they engage in academic and social activities at the university as well as the forms of engagements thereof. When asked what they do when they have academic and social challenges that affect their learning, one of the high performers said: "Injobo ithungelwa ebandla": meaning that it is not a shame to ask for advice from others i.e., seek advice from those who know. This powerful expression was used when students emphasized the significance of a mutually beneficial social and academic relationship as well as the importance of consultation with academic staff, tutors, and fellow classmates.

Focus group discussions also revealed that students were unable to buy learning materials like books because of the exorbitantly high prices of these prescribed books. Students had devised their survival strategies in mitigation of financial challenges. These strategies were contained in this expression: "Inyoni yakhela ngamaqubu enye": meaning a bird builds its nest using other birds' feathers. This expression featured when students said they did not have books; they could not afford to buy them. They borrowed from one another and shared 
educational resources instead of buying books because books are used for one semester only, and the high cost could not be justified against the time set for them to use the books.

The students believed in collaboration, working together, the value of brotherhood, the spirit of accepting common social practices and challenges, similar academic difficulties, barriers to learning, financial problems and a wide range of social challenges. One group agreed that despite all odds: "Umuntu ngumuntu ngabantu”: meaning that a person is a person through other persons or a person is a person because of other people. The collaborative learning informed by group work, teamwork and the beneficial or reciprocal nature of friendship found value in this expression. That was the context in which the following expression was used: "Izinyoni zansibanye zindiza ndawonye"; meaning that the birds of the same feathers flock together. There were instances where students could not find benefits from other group members, and they ended up leaving those group members or excluding those that do not share the same values as they do.

\section{DISCUSSIONS: STUDENT ENGAGEMENT AND CULTURAL HERITAGE}

The findings in this study suggest that the students from a fairly homogeneous group are much likely to share a common culture. During interviews, students pronounced their cultural pride and heritage. That was a declaration that prompted further expansion. We argue that students' cultural orientations have implications in their academic and social integration as well as academic performance in their first year of study. In validating this claim; Wacquant (1998, 216) argues that the cultural capital, educational credentials, family background or familiarity with the bourgeois culture are the major determinant of life chances under the cloak of individual talent and academic meritocracy. The implication of Wacquant's claim is that students who have a cultural deficiency on what is required at the university are most likely to face academic challenges that will impede their academic performance. Further, first-year students' earlier academic experiences affect their performance.

The students' cultural symbols have a direct impact on learning and teaching and need to be understood with the aim to enhance student engagement. This study has found that the lack of confidence as a result of a poor command of English as a language of learning contributes to how first-year students interact with university lecturers both inside and outside the classroom environment. Cultural symbols point out that students rely on collegial learning with peers. Collegial groupings need to be encouraged and tutorials promoted as students feel safe and free on their own and with their peers and would rather collaborate with their peers than a lecturer. Further, encourage more blended learning approach and materials for blended learning to be made culture sensitive. 
The findings suggest that the students' cultural orientation and culture shock become the first barrier to effective earlier academic integration. Students were not familiar with large class sizes and were not accustomed to the use of technology in teaching as well as the continuous and uninterrupted use of English as the language of teaching at the university. Most of the students agreed that they relied on code switching because the mother-tongue (isiZulu) was not frequently used to explain foreign key concepts during lectures. Also, as they conceded, the students experienced challenges with the accent of lecturers particularly those lecturers who were foreign nationals. How then do these students' cultural repertoires affect the manner in which students engage and how can these be mitigated? This calls for a need to relook at the pedagogical practices employed by lecturers.

First-year students' timely structured academic, social and cultural integration is critical for student academic performance, persistence and success at University. Tinto $(2014,21)$ argues that "student success does not arise by chance, nor does substantial improvement in institutional rates of student retention and graduation". In the same argument Tinto (2012) concludes that student success is the result of intentional and proactive actions, policies, planning, programmes and interventions directed towards the success of all students in an institution. This further suggests a call for a renewed pedagogical practice.

Students' cultural orientations influence the extent to which students integrate both socially and academically. These cultural orientations present challenges as students generally present a poor or a low command of English as a spoken language and also as medium of instruction. Secondly poor levels of contact with academic staff are challenged as most of the time, students are expected to use English to communicate with academic staff and have a problem to express their problems freely and convincingly. DiMaggio's $(1982,190)$ claim is that teachers "communicate more easily with students who participate in elite status cultures, give them more attention and special assistance, and perceive them as more intelligent or gifted than students who lack cultural capital". It can be said that the issue of language is critical in understanding the student engagement phenomenon.

The study found that most students were generally brought up by parents with high illiteracy rates and homes where reading materials were not commonly available or were nonexisting and that the majority of students were first-generation students. These findings suggest that the majority of students were never exposed to the culture of reading at home except for the prescribed set books they were exposed to at schools. Students then found themselves in the university environment which suddenly demands high levels of critical engagement with complex academic texts. This suggests the impact of students' family background has on their performance at university and determines the possibilities of uninterrupted progress and success 
at the university.

Culture perpetuates an identity that needs to be understood as consideration for both pedagogical and andragogical practices and is fundamental in various in the educational contexts. Firstly, one does not question authority as that is seen as sign of disrespect. Thus, this type of cultural orientation contributes immensely to low or poor participation in class discussions. Secondly, direct eye contact with an elder or a person in authority; whereas in the English culture that shows that one is listening with respect and is not hiding anything; while in the Zulu culture looking at your senior straight in the eye is a sign of disrespect; signalling cultural conflict. This further makes it difficult for students to approach academic staff members in their offices to seek further assistance. The cultural supposition is that being in similar spaces with seniors is traditionally not a common phenomenon, thus challenging access to consultation and further engagement with academic staff members. Entry into these spaces warrants some form of hierarchy or protocol, or the prospective entrant needs to possess a certain level of linguistic capital and the clarity of purpose.

Thirdly large class sizes present a situation wherein students sit on the floor, females who traditionally wear dresses are unable to sit comfortably and concentrate during lectures, particularly when a male lecturer is in front of the class presenting. Consequently, attendance of classes for some female students could be affected, particularly if they arrive late for classes and know that they may not have a space to sit, they may either opt to stand in the doorway and battle to hear the lecturer or opt not to enter the class. The sitting arrangement in the Zulu culture is known; men generally sit on the right-hand side, those in positions of authority to the front and women sit on the left-hand side. Further challenges posed by theatre type of setting is that sitting makes young men and women equal. While generally Zulu women maidens may wear tops that could be revealing the upper body as well as skirts that are very short, they have a particular way of sitting, where knees and ankles would touch and tilted to one side ensuring that the privacy and non-exposure to any person in front of them.

The above argument finds conviction and strength that is is uncustomary in the Zulu tradition as such an act could be viewed as both provocative and inviting. The challenge this presents to some females is that they sometimes miss lectures, if they can't find a place to sit in the seats available in the lecture halls. They mentioned that it is problematic to sit on the floor facing a male lecturer while wearing dresses. These are considerations that univesrities need to take into account, for an example to minimize class sizes to correspond with the exiting infrastructure. While the provision of larger venues may solve the problem, the influx of students into South African universities is a phenomenon that challenges infrastructure amongst other things. The provision of larger venues could be a long-term solution. This study 
challenges institutions to be cognizant of this particular cultural dynamic and others as these impact on students' academic performance. Further, we are challenging lecturers to be critical of their pedagogical practises.

Findings from this study on students' cultural orientation finds support in Ramrathan (2013) the self-perpetuation of students' group identities has proven to work positively for some groups in this study. Students that tend to perform well academically are mostly active members of study groups, while students that perform badly academically are mostly detached from active group activities. The findings from this study also indicate that the students whose academic performance is high work in groups; the collective engagement of students to find common solutions to similar problems. Also, the findings from one-on-one interviews with students that showed exceptionally high levels of academic performance revealed:

- Collaborative learning. Students formed study groups with fellow students, and had their own tutorials led by other fellow groupmates.

- Extra time for learning. Group rules required students to do some work on their own before study group session. This they believed enabled them to actively participate in discussion. This also enabled them to ask relevant questions.

- Sharing of learning resources. Students exchanged and shared study materials and books.

- Regular Lecturer Consultation. They consulted with their lecturers after lectures to seek clarity on areas that they may have not understood in class, on assessment activities and sought feedback on assignments.

- Use of Technology (mobile devices). Students recorded lecturers using their mobile phones and had numerous opportunities to repetitively listen to lectures at their convenience, pace and need.

- Discussion assessment test result. After the tests and assignments, students made time to talk to lecturers about why they performed in the manner in which they did.

The implications for the university is to increasingly go beyond the recognition of the demographic diversity of our students and to engage more deeply into the cultural diversities that have come to inform ways of being, ways of engaging socially and ways of engaging materially within (higher) education environments. Through a deeper engagement on cultural signals, the architecture of higher education institutions could be re-imagined to consider these cultural signals to align with student's cultural world views and cultural practices so that deep fractures within students do not emerge within their first years at university. The deep fractures 
are, as this article argues, debilitating to first-year students in terms of their attendance to lectures, being interactive in classes and in seeking support outside of lecture times. Hence the architecture is not only about building spaces. Rather it includes the interactive spaces that students are likely to enter and where their entry could be compromising to them through taken for granted processes and practices. Hence the re-imagination of the architecture of higher education may be a vantage perspective to understand the needs of students in a more culturally sensitive manner to allow for a smoother transition into higher education studies.

\section{CONCLUSION}

It is necessary for future studies to pay particular attention to the institutional culture of universities and explore whether any discrepancies between student and institutional culture exists given that a dominant student culture usually dictates the institutional culture. Cultural issues or gaps between the university and students require further exploration. It becomes necessary, for the university to consider initiatives that will present scientific evidence of students' cultural orientation with an intention to understand the exact cultural dynamics that students present. This scholarship did not intend to provide findings that would reinforce African Languages in universities as means to enhance access and success of students. Such scholarly engagement is necessary as it would further provide avenues that would privilege students' basic rights and cultural identity.

This article has argued that over and above the common discourses of student engagement that involve the critical elements which involve students' behavioural, emotional and cognitive elements, the students' cultural signals and cultural orientation are critical components that need to be understood in order to enhance student academic performance. Notwithstanding the components that have been argued on the respective roles of universities and students in understanding student engagement, this article has argued that first-year students' earlier integration is critical and needs to include cultural understanding of students as new entrants into the university environment or university community. Also, cultural integration best finds value when structured to respond to student academic performance and the role institutions play to reciprocate culture. The argument presented consents that social and academic integration are pivotal in the same way that cultural integration is, and, is best effective when structured and occurs in the earlier stages of the first-year students' life at university.

There is reason to believe that academic success and student performance are related to students' cultural orientation. Students' cultural repertoires like relationship with authority hinder students' interaction with academic staff members. Gender stereotypes are also critical elements that need to be understood within the discourse of student engagement as these 
stereotypes affect student participation in class, in small groups and interaction with academic staff. Critical to understating student engagement is the students' homogeneity; in this particular context, it shows that a collective solution to common academic problems could provide alternative pedagogical methodologies. Allowing students to form discussion forums is within their native orientation of discussing and debating common challenges and arriving at a common solution. Students' cultural orientation provides the newer lens in understanding student engagement, academic performance and student success.

\section{REFERENCES}

Axelson, R. D. and A. Flick. 2011. "Defining Student Engagement." Change: The Magazine of Higher Learning 43(1): 38-43. DOI: 10.1080/00091383.2011.533096. 28 March 2014, At: 05:26.

Badat, S. 2010. "The challenges of transformation in higher education and training institutions in South Africa." Development Bank of Southern Africa, 8.

Bourdieu, P. 1992. Language and symbolic power. Harvard University Press.

Boyd, B. 2008. Art as adaptation: A challenge. Style 42(2-3): 138-143.

CHE see Council on Higher Education.

Council on Higher Education. 2016. South African Higher Education Reviewed. Two decades of democracy. Pretoria: Council on Higher Education

Council on Higher Education. 2017. Vitalstats 2015, Public Higher Education 2017. Pretoria: Council on Higher Education.

Council on Higher Education. 2019. Vitalstats 2017, Public Higher Education 2017. Pretoria: Council on Higher Education.

DiMaggio, P. 1982. "Cultural capital and school success: The impact of status culture participation on the grades of US high school students." American Sociological Review: 189-201.

Fitzgerald, H. E., K. Bruns, S. T. Sonka, A. Furco, and L. Swanson. 2016. "The centrality of engagement in higher education." Journal of Higher Education Outreach and Engagement 20(1): 223-244.

Govender, S. 2014. "Successful access at the University of KwaZulu-Natal, South Africa through Ubuntu: The student voice." Indilinga African Journal of Indigenous Knowledge Systems 13(1): $11-27$.

Hlengwa, A., S. McKenna, and T. Njovane. 2018. "The lenses we use to research student experiences." Higher Education Pathways: 149.

Kahu, E. R. and K. Nelson. 2018. "Student engagement in the educational interface: Understanding the mechanisms of student success." Higher Education Research \& Development 37(1): 58-71.

Keesing, R. M. 1974. "Theories of culture." Annual Review of Anthropology 3: 73-97.

Krause, K. L. and H. Coates. 2008. "Students' engagement in first-year university." Assessment \& Evaluation in Higher Education 33(5): 493-505.

Kroeber, A. L. and C. Kluckhohn. 1952. Culture: A critical review of concepts and definitions. Papers. Peabody Museum of Archaeology \& Ethnology, Harvard University.

Kuh, G. D. 2006. "Built to Engage: Liberal Arts Colleges and Effective Educational Practice.” In Liberal Arts Colleges in American Higher Education (ACLS Occasional Paper), ed. F. Oakley, 122-150. New York: American Council of Learned Societies.

Kuh, George D., Ty M. Cruce, Rick Shoup, Jillian Kinzie, and Robert M. Gonyea. 2008. "Unmasking the Effects of Student Engagement on First-Year College Grades and Persistence." The Journal of Higher Education 79(5): 540-563. DOI: 10.1080/00221546.2008.11772116. 
Letseka, M. and S. Maile. 2008. High university drop-out rates: A threat to South Africa's future. Pretoria: Human Sciences Research Council.

McGhie, V. F. 2012. Factors impacting on first-year students' academic progress at a South African university. Doctoral dissertation, Stellenbosch University.

McKay, J. and M. Devlin. 2016. "Low income doesn't mean stupid and destined for failure': challenging the deficit discourse around students from low SES backgrounds in higher education." International Journal of Inclusive Education 20(4): 347-363.

Mdepa, Wandisile and Lullu Tshiwula. 2012. "Student diversity in South African higher education." Widening Participation and Lifelong Learning 13(1): 19-33.

Meek, V. L., L. Goedegebuure, R. Santiago, and T. Carvalho. (Eds.). 2010. The changing dynamics of higher education middle management. (Vol. 33). Springer Science \& Business Media.

Mesoudi, A. 2016. Cultural evolution: A review of theory, findings and controversies. Evolutionary Biology 43(4): 481-497.

Ramrathan, L. 2013. "Towards a conceptual framework for understanding student dropout from HEIs." South African Journal of Higher Education 27(1): 209-220

Ramrathan, L. and G. Pillay. 2015. "Re-imagining and expanding the discourse of student access, through put and drop-out within the South African higher education context." Alternations 17(2015): 6-27.

Reckwitz, A. 2002. "The status of the 'material' in theories of culture: From 'social structure' to 'artefacts'." Journal for the Theory of Social Behaviour 32(2): 195-217.

Scott, I., N. Yeld, and J. Hendry. 2007. "A case for improving teaching and learning in South African Higher Education." Higher Education Monitor No. 6. The Council on Higher Education, Pretoria.

Statistics South Africa. 2012. Census 2011 Census in brief. Pretoria. Statistics South Africa. Cape Town.

Strydom, F., G. Kuh, and M. Mentz. 2010. "Enhancing success in South Africa's higher education: Measuring student engagement." Acta Academica 42(1): 259-278.

Strydom, J. F. and M. Mentz. 2010. South African Survey of Student Engagement. (SASSE) - Focusing the Student Experience on Success through Student Engagement. CHE Publication. Pretoria.

Tinto, V. 2012. "Enhancing student success: Taking the classroom success seriously." The International Journal of the First Year in Higher Education 3(1): 1-8.

Tinto, V. 2014. "Reflective practice. Tinto's South Africa lectures." Journal of Student Affairs in Africa 2(2): 5-28 | 2307-6267 | DOI: 10.14426/jsaa.v2i2.66

Trowler, V. 2010. "Student engagement literature review." The Higher Education Academy 11: 1-15.

Van Zyl, A. 2013. "Teaching the students we have: Two perspectives on first year students at the University of Johannesburg and the UJ First Year Experience initiative." Unpublished Doctoral thesis, University of Johannesburg, Johannesburg.

Wacquant L. 1998. "Pierre Bourdieu." In Key Sociological Thinkers, ed. R. Stones. Palgrave, London. https://doi.org/10.1007/978-1-349-26616-6_17. 